\title{
The role of functional, social, and mobility dynamics in facilitating older African Americans participation in clinical research
}

This article was published in the following Dove Press journal:

Open Access Journal of Clinical Trials

7 April 2017

Number of times this article has been viewed

\author{
Eve T Shapiro ${ }^{1,2}$ \\ Jay $T^{\text {Schamel }}{ }^{2}$ \\ Kimberly A Parker ${ }^{3}$ \\ Laura A Randall, \\ Paula M Frew ${ }^{1,2,4}$ \\ 'Division of Infectious Diseases, \\ Department of Medicine, Emory \\ University School of Medicine, \\ ${ }^{2}$ Department of Behavioral Sciences \\ and Health Education, Emory \\ University Rollins School of Public \\ Health, Atlanta, GA, ${ }^{3}$ Department \\ of Health Studies, Texas Women's \\ University, Denton, TX, ${ }^{4}$ Hubert \\ Department of Global Health, Emory \\ University Rollins School of Public \\ Health, Atlanta, GA, USA
}

Purpose: Older African Americans experience disproportionately higher incidence of morbidity and mortality related to chronic and infectious diseases, yet are significantly underrepresented in clinical research compared to other racial and ethnic groups. This study aimed to understand the extent to which social support, transportation access, and physical impediments function as barriers or facilitators to clinical trial recruitment of older African Americans.

Methods: Participants ( $\mathrm{N}=221)$ were recruited from six African American churches in Atlanta and surveyed on various influences on clinical trial participation.

Results: Logistic regression models demonstrated that greater transportation mobility (odds ratio $[\mathrm{OR}]=2.10 ; p=0.007)$ and social ability $(\mathrm{OR}=1.77 ; p=0.02)$ were associated with increased intentions of joining a clinical trial, as was greater basic daily living ability $(\mathrm{OR}=3.25 ; p=0.03)$, though only among single participants. Among adults age $\geq 65$ years, those with lower levels of support during personal crises were more likely to join clinical trials ( $\mathrm{OR}=0.57 ; p=0.04)$.

Conclusion: To facilitate clinical trial entry, recruitment efforts need to consider the physical limitations of their potential participants, particularly basic physical abilities and disabilities. Crisis support measures may be acting as a proxy for personal health issues among those aged $>65$ years, who would then be more likely to seek clinical trials for the personal health benefits. Outreach to assisted living homes, hospitals, and other communities is a promising avenue for improved clinical trial recruitment of older African Americans.

Keywords: clinical trials, aging, minority populations, African Americans, physical disabilities

\section{Introduction}

Older Black/African American adults have been underrepresented in clinical trials compared to their Caucasian peers. ${ }^{1-4}$ Enrollment disparity has been so widely recognized that the US National Institutes of Health (NIH) released broader guidelines in 1994 to address the historical problem of under enrollment of racial and ethnic minorities and women. ${ }^{5}$ Disparate rates of participation are problematic, as clinical trial findings become difficult to generalize; indeed, medications, devices, interventions, and treatments may not be indicated for specific demographic groups based upon findings derived from populations lacking diversity. ${ }^{1}$ Recent reviews of participant recruitment and enrollment in cancer, heart failure, surgical oncology, and lung injury trials reflect racial- and gender-based enrollment disparities that have resulted in reduced generalizability. ${ }^{6-9}$

The factors contributing to clinical trial motivation among diverse populations include perceived participation advantages ranging from special access to health care and premarket treatments to a broader sense of purpose (altruism). ${ }^{10,11}$ Yet, most of the prior research on clinical trial participation among African Americans has
Correspondence: Paula M Frew Division of Infectious Diseases, Department of Medicine, Emory University School of Medicine, 1760 Haygood Road, Suite W300, Office W327, Atlanta, GA 30322, USA

Tel +l 4047128546

Fax +I 4047124193

Email pfrew@emory.edu 
highlighted potential participants' psychosocial challenges, such as distrust of researchers, unexpected costs, and lack of familiarity with clinical studies. ${ }^{12-14}$ More recently, however, attention has been given to factors facilitating access to care and the health and well-being of older adults such as mobility, social participation, and neighborhood characteristics such as availability of trials in the residential area. ${ }^{15,16}$ These factors have demonstrated an influence on health decision making among older Black/African American individuals (e.g., vaccination). ${ }^{17,18}$

A call to action has been issued for novel strategies to improve clinical trials participation rates among older African Americans, who experience greater morbidity and mortality for many infectious and chronic diseases (e.g., HIV, colorectal cancer, diabetes, hypertension), which could be reduced through new medical advances. ${ }^{1,19-24}$ Accounting for physical disability and functional impairments typical of older persons is therefore critical to the assessment of a broader scope of socioenvironmental factors that may be important determinants in realizing greater diversity in future clinical trials. ${ }^{25}$

This study examines other factors that may influence enrollment decision making among this highly vulnerable group, including personal, social, and community barriers and facilitators. This study assesses considerations associated with clinical research participation drawing upon the socioecological framework for human behavior. ${ }^{26}$ Thus, we examined the interaction between individual-level factors (sociodemographics, physical abilities such as strength and mobility, social abilities, errand transportation availability, and other independent assessments of functional abilities), interpersonal-level factors (social support and crisis support), and community-level factors (transportation access).

\section{Methods}

\section{Study procedures}

\section{Study design and sample}

The data were collected from a cohort of 221 African Americans recruited in metropolitan Atlanta, Georgia through a cluster randomized controlled trial design. ${ }^{26}$ In conjunction with this analyses, we also evaluated the feasibility and potential effectiveness of the "Dose of Hope" intervention to test whether delivery of a three-session group intervention increased the proportion of older African Americans who enrolled in an array of chronic and infectious disease-related clinical trials. ${ }^{27}$ Our inclusion criteria included those who self-reported being primarily Black/African American, $\geq 50$ years of age, a congregant of one of the six African American participating churches, and having no previous history of clinical research participation. All participants provided written informed consent.

\section{Data collection}

We conducted surveys with all enrolled participants at baseline and 3-month time points between January 2013 and May 2014. The surveys measured various influences on clinical trial participation, designed using established macro- and micro-theoretical models, including the socioecological model and an extended theory of reasoned action. ${ }^{28-33}$ As such, the measures include those pertaining to nested influences from the community- to individual-level, as well as moderating and mediating influences on attitudes and social norms toward trial participation. ${ }^{24-26}$ Items analyzed from this study included linked data from the baseline and 3-month questionnaires containing sociodemographic questions (i.e., age, gender, education level, income, and relationship status) as well as functional disability and social support scales. ${ }^{34,35}$

The primary outcome was the self-reported intention that individuals would participate in clinical research. It was measured through a single item on the baseline survey, "On a scale from 0 (definitely not) to 10 (definitely so), rank your likelihood of joining a medical research study within the next 6 months." For this analysis, we dichotomized responses using a median split, with responses of 6 or below categorized as less likely to join a study and those 7 or higher categorized as likely to join a clinical study.

\section{Ethical considerations}

The project was reviewed and approved by the Institutional Review Board of Emory University (IRB 00057210).

\section{Physical and social ability measures}

Participant's physical abilities ("Functional Ability") and available social support ("Social Support") were measured using multi-item survey instruments. Functional Ability was assessed through 15 items measuring ability in daily living and 4 questions measuring long-term physical abilities, developed from the "Functional Status Questionnaire." ${ }^{34}$ Social Support consisted of a 19-item validated instrument on medical outcomes and social support. ${ }^{35}$

Social Support and Functional Ability scales were transformed into factor scores for analysis. An expected maximum imputation was used to impute missing items using other components of the same scale when $>50 \%$ of the scale items were completed. For each instrument, principal component extraction was performed followed by varimax rotation. Significant factor loadings were identified as loadings over 
0.5 , and crossloading items were removed. Only two items were removed, both from the Social Support scale: "How often do you have someone to take you to the doctor if you needed it?" and "How often do you have someone to confide in or talk to about yourself or your problems?" The number of factors was selected for both an eigenvalue over 1.0 and interpretability.

Factor internal reliability was assessed with Cronbach's alpha, with an alpha $>0.70$ considered acceptably reliable. All resulting factors from the Functional Ability and Social Support scales had alpha $>0.75$. The four items measuring long-term physical abilities were analyzed via factor analysis but had poor internal consistency, with alpha $<0.70$. Finally, standardized factor scores were computed using the regression method.

The Functional Ability scale scores resulted in four subscales: "Basic Ability", "Strength and Mobility", "Social Ability", and "Errand Transportation". Basic Ability measures the participant's independence in basic daily life activities, such as dressing, feeding, or bathing themselves. Strength and Mobility measures instrumental daily life activities requiring more functional ability, such as chores, walking outside the home, and using public transportation. Social Ability measures functional ability necessary to support social activities, such as the ability to participate in community activities or visit others. Errand Transportation measures independence in transportation, like the ability to drive and do errands such as shopping.

The larger Social Support scale resulted in two subscales: "Social Support" and "Crisis Support". Social Support measures the availability of social support in day-to-day life, such as the availability of others who give advice, show love and affection, or who are available for recreation. Crisis Support measures available support from others in the case of crisis or loss of functional ability, such as help when confined to a bed or availability of someone to talk to about a crisis.

\section{Analysis}

All analyses were completed using Statistical Package for the Social Sciences (SPSS) version 22 (SPSS, Inc., Chicago, IL, USA). Descriptive statistics were obtained for all variables of interest. Bivariate odds ratios (ORs) and prevalence ratios (PRs) were estimated to explore direct associations between participant intention to join clinical research and sociodemographic factors, Functional Ability measures, and Social Support measures. Bivariate ORs and 95\% confidence intervals were estimated using bivariate logistic regression, and bivariate PRs and confidence intervals estimated by bivariate log binomial regression.
A logistic regression model was fit to assess the individual and cumulative associations with the dichotomized outcome. A Poisson regression using robust covariance estimates was also fit to estimate adjusted PRs. The robust Poisson model was chosen over the log-binomial model to facilitate convergence of estimates.

Of the 221 persons enrolled in the study, 7 participants did not complete the outcome item at baseline ( $3 \%$ missing), 3 were missing age information (1.4\% missing), and 23 were missing factor scores for either the Functional Ability or Social Support scales (10.4\%); the resulting analysis included 191 complete cases (13.6\% overall). The multivariable models included two-way interactions between factor scores and demographic variables (age, gender, income, education, and relationship status). Collinearity between independent factors within each model was assessed using variance inflation factors (VIFs).

\section{Results}

\section{Participant and sample characteristics}

At baseline, 221 participants completed the survey, while 211 completed the 3-month survey. The mean age was 63.6 years (standard deviation $[\mathrm{SD}]=7.50$ ), though ages ranged from 50 to 90 (Table 1). There were 173 females $(78.3 \%)$ and 48 males $(21.7 \%)$. The majority of participants had an associate's degree or higher $(n=142,64.3 \%)$. There was a moderate spread of household income, with the plurality claiming an income below $\$ 20,000(n=61,27.6 \%)$ and fewest claiming a household income over $\$ 100,001(n=13,5.9 \%)$. Participant employment varied, with the fewest claiming part-time employment $(\mathrm{n}=18,8.1 \%)$ and the most responding that they were retired $(n=85,38.5 \%)$. Participants were primarily married $(n=102,46.2 \%)$ or separated/divorced $(n=59,26.7 \%)$. Table 1 also displays the sociodemographic characteristics of the 191 participants for whom we could include in the multivariable logistic regression model as they had complete case data (labeled "complete cases").

The outcome variable, likelihood of joining a clinical study at baseline, had a mean score of $5.83(\mathrm{n}=214, \mathrm{SD}=2.68)$ and a median score of $6(0=$ definitely not, $10=$ definitely so $)$. The most frequently selected score was a 5 with 42 responses and $19.0 \%$ of all responses.

\section{Functional Ability and Social Support scales}

The 15 Functional Impairment items resulted in four factors: Basic Ability ( 5 items, $\alpha=0.97$ ), Strength and Mobility ( 5 items, $\alpha=0.97$ ), Social Ability ( 3 items, $\alpha=0.97$ ), and 
Table I Sociodemographic characteristics of study participants

\begin{tabular}{|c|c|c|}
\hline Item & Total sample (n=22I), n (\%) & 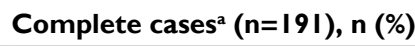 \\
\hline \multicolumn{3}{|l|}{ Age, years (missing, $n=3$ ) } \\
\hline $50-54$ & $23(10.4)$ & $22(110.5)$ \\
\hline $55-59$ & $39(17.6)$ & $35(18.3)$ \\
\hline $60-64$ & $58(26.2)$ & $50(26.2)$ \\
\hline $65-69$ & $50(22.6)$ & $46(24.1)$ \\
\hline $70-79$ & $41(18.6)$ & $33(17.3)$ \\
\hline$\geq 80$ & $7(3.2)$ & $5(2.6)$ \\
\hline \multicolumn{3}{|l|}{ Gender } \\
\hline Female & $173(78.3)$ & $146(76.4)$ \\
\hline Male & $48(2 \mid 0.7)$ & $45(23.6)$ \\
\hline \multicolumn{3}{|l|}{ Race } \\
\hline African American/Black & $217(98.2)$ & 187 (97.9) \\
\hline Multiracial/multicultural & $4(10.8)$ & $4(2.1)$ \\
\hline \multicolumn{3}{|l|}{ Ethnicity (missing, $n=45$ ) } \\
\hline Non-Hispanic & $175(79.2)$ & $157(82.5)$ \\
\hline Hispanic/Latino/Chicano & $\mathrm{I}(0.5)$ & $\mathrm{I}(0.5)$ \\
\hline \multicolumn{3}{|l|}{ Highest level of education } \\
\hline Kindergarten-8th grade & $3(10.4)$ & $2(10.0)$ \\
\hline 9 th-I Ith grade & $10(4.5)$ & $6(3.1)$ \\
\hline High school graduate/GED & $66(29.9)$ & $60(310.4)$ \\
\hline Technical/vocational/associates & $66(29.9)$ & $55(28.8)$ \\
\hline Bachelor's degree & $37(16.7)$ & $33(17.3)$ \\
\hline Master's degree & $33(14.9)$ & $29(15.2)$ \\
\hline Doctorate & $6(2.7)$ & $6(3.1)$ \\
\hline \multicolumn{3}{|c|}{ Household income (missing, $n=23$ ) } \\
\hline$<\$ 20,000$ & $61(27.6)$ & $50(26.2)$ \\
\hline$\$ 20,00 \mathrm{I}-\$ 40,000$ & $49(22.2)$ & $42(22.0)$ \\
\hline$\$ 40,001-\$ 60,000$ & $36(16.3)$ & $34(17.8)$ \\
\hline$\$ 60,001-\$ 80,000$ & $20(9.0)$ & $18(9.4)$ \\
\hline$\$ 80,001-\$ 100,000$ & $19(8.6)$ & $17(8.9)$ \\
\hline$>\$ 100,001$ & $13(5.9)$ & $13(6.8)$ \\
\hline \multicolumn{3}{|l|}{ Employment (missing, $n=8$ ) } \\
\hline Employed - full time & $43(19.5)$ & $38(19.9)$ \\
\hline Employed - part time & $18(8.1)$ & $18(9.4)$ \\
\hline Unemployed & $37(16.7)$ & $32(16.8)$ \\
\hline Other (retired, $n=85,44.4 \%$ ) & $115(52.0)$ & $97(50.8)$ \\
\hline \multicolumn{3}{|l|}{ Relationship status } \\
\hline Single/never married & $24(10.9)$ & $20(10.5)$ \\
\hline Married/domestic partner & $102(46.2)$ & 89 (46.6) \\
\hline Divorced/separated & $59(26.7)$ & $5 \mathrm{I}(26.7)$ \\
\hline Widowed & $35(15.8)$ & $30(15.7)$ \\
\hline Other & $\mathrm{I}(0.5)$ & $\mathrm{I}(0.5)$ \\
\hline
\end{tabular}

Note: a Complete cases are those participants who have responses for all variables included in the logistic regression model.

Abbreviations: GED, General Education Development high school equivalency diploma.

Errand Transportation ( 2 items, $\alpha=0.97$ ). The two resulting factors for Social Support were Crisis Support (3 items, $\alpha=0.85$ ) and Social Support (14 items, $\alpha=0.97$ ). The four long-term ability items resulted in a single factor with $\alpha=0.698$; because the $\alpha$ was not $>0.70$, these items were treated individually for analysis.

Items included in the Functional Ability factor scales demonstrated high levels of ability (Table 2). Within Basic Ability, average scores ranged from 3.91 to 3.97 (1=no difficulty, $4=$ too difficult to do). In the factor of Strength and
Mobility, the 5 items ranged from 3.11 to 3.76, representing high levels of strength or low mobility impairment. Within the category of Social Ability, scores ranged from 3.72 to 3.84, indicating higher levels of social abilities. Errand Transportation scores averaged $3.92(\mathrm{SD}=0.31)$ for "... driving a car" and $3.84(\mathrm{SD}=0.39)$ for "...doing errands", demonstrating high ability to complete errands.

The Social Support factors had mean scores ranging from 3.87 to 4.30 ( $1=$ none of the time, $5=$ all of the time), indicating high average availability of social support 
Table 2 Functional ability scale: resultant factors and factor loadings

\begin{tabular}{|c|c|c|c|c|c|}
\hline Factor "In the past month, have you had difficulty with..." & Mean $^{a}$ & SD & Min & Max & Factor loading \\
\hline \multicolumn{6}{|l|}{ Basic Ability ( $\alpha=0.879,5$ items $)$} \\
\hline Feeding yourself? & 3.97 & 0.21 & 2 & 4 & 0.78 \\
\hline Dressing yourself? & 3.95 & 0.25 & 2 & 4 & 0.90 \\
\hline Moving in and out of bed? & 3.91 & 0.31 & 2 & 4 & 0.76 \\
\hline Bathing yourself? & 3.95 & 0.23 & 2 & 4 & 0.90 \\
\hline Walking around your home? & 3.91 & 0.29 & 2 & 4 & 0.59 \\
\hline \multicolumn{6}{|l|}{ Strength and Mobility ( $\alpha=0.86 \mathrm{I}, 5$ items) } \\
\hline Walking several blocks? & 3.58 & 0.75 & 1 & 4 & 0.80 \\
\hline Doing house chores such as cleaning? & 3.76 & 0.53 & I & 4 & 0.62 \\
\hline Using public transportation? & 3.72 & 0.69 & 1 & 4 & 0.61 \\
\hline Lifting heavy objects? & 3.18 & 0.92 & 1 & 4 & 0.82 \\
\hline Doing physical activity such as running? & 3.11 & 10.05 & 1 & 4 & 0.85 \\
\hline \multicolumn{6}{|l|}{ Social Ability ( $\alpha=0.803,3$ items) } \\
\hline Visiting other peoples' homes? & 3.80 & 0.50 & 1 & 4 & 0.80 \\
\hline $\begin{array}{l}\text { Participating in community activities, such as religious services, social activities, } \\
\text { or volunteer work? }\end{array}$ & 3.84 & 0.44 & I & 4 & 0.82 \\
\hline Taking care of other people such as family members? & 3.72 & 0.64 & I & 4 & 0.53 \\
\hline \multicolumn{6}{|l|}{ Errand Transportation $(\alpha=0.752,2$ items $)$} \\
\hline Doing errands, such as grocery shopping? & 3.84 & 0.39 & 2 & 4 & 0.63 \\
\hline Driving a car? & 3.92 & 0.31 & 2 & 4 & 0.88 \\
\hline
\end{tabular}

Notes: ${ }^{a}$ = Too difficult to do; $4=$ no difficulty; to aid interpretation, this scale has been reverse-coded from the original survey instrument.

Abbreviations: Max, maximum; Min, minimum; SD, standard deviation.

(Table 3). Similarly, items included in the Crisis Support factor had means of 3.67-4.03, also indicating moderately high levels of crisis support.

\section{Associations with likelihood of joining clinical trials \\ Bivariate analysis}

Bivariate ORs and PRs were estimated to explore direct associations between participant intentions to join clinical trials and sociodemographic factors, Social Support, and Functional Ability (Table 4). Those participants with greater access to Errand Transportation indicated greater intention to participate in clinical research ( $\mathrm{OR}=1.77,95 \% \mathrm{CI}$ : [1.09, $2.86], p=0.02 ; \mathrm{PR}=1.24[1.00,1.54], p=0.05)$. No other statistically significant bivariate associations were found amongst the Functional Ability measures, Social Support measures, or tested sociodemographic factors.

\section{Multivariable models}

Multivariable logistic and robust Poisson models were run to assess the relationships between sociodemographics, physical ability, social support, and the outcome variable. The final model was selected according to potential influences on clinical trial participation identified by previous research and theory. ${ }^{15,36}$ We included two interaction terms based on the hypotheses that the effect of available Crisis Support would be moderated by age and that Basic Ability would be most important for single participants. The final model included four measures of sociodemographics, the two social support factors, the four functional impairment factors, and the two interaction terms. The four long-term physical ability items were not included due to potential redundancy with the Basic Ability factor score. Multicollinearity was assessed using VIFs, and all factors were below five so within acceptable range.

The final logistic regression model was significant $\left(\mathrm{X}^{2}=22.24, p=0.03\right)$ with a Nagelkerke $R^{2}$ score of 0.15 . The Hosmer and Lemeshow fit test was nonsignificant $\left(\mathrm{X}^{2}=5.97, p=0.6\right)$, indicating a lack of evidence for poor fit. The statistically significant factors were very similar between the multivariable logistic and robust Poisson models. Two independent variables were significantly related to likelihood to join a clinical study: greater intentions to join clinical trials were associated with greater Social Ability $(\mathrm{OR}=1.77,95 \%$ CI: [1.09, 2.87], $p=0.02 ; \mathrm{PR}=1.42$ [1.09, 1.86], $p=0.009)$ and greater access to Errand Transportation $(\mathrm{OR}=2.09$ [1.22, 3.57], $p=0.007 ; \mathrm{PR}=1.57$ [1.14, 2.19], $p=0.008$ ) (Table 5).

Two more variables were significantly associated with the likelihood to join clinical trials for certain values of a moderating factor. Greater intention to join clinical trials was associated with greater Basic Ability, but only among single participants $(\mathrm{OR}=3.25[1.16,9.10], p=0.03 ; \mathrm{PR}=2.08$ $[1.24,3.48], p=0.005)$. Crisis Support was not significantly 
Table 3 Resultant factors and factor loadings for Social Support scale

\begin{tabular}{|c|c|c|c|c|c|}
\hline Factor (“How often do you have...”) & Mean $^{\mathbf{a}}$ & SD & Min & Max & Factor loading \\
\hline \multicolumn{6}{|l|}{ Social Support ( $\alpha=0.974$, I 4 items) } \\
\hline Someone who shows you love and affection & 4.30 & 0.87 & 2 & 5 & 0.72 \\
\hline Someone to have a good time with & 4.15 & 0.94 & I & 5 & 0.81 \\
\hline Someone to give you information to help you understand a situation & 4.12 & 0.95 & I & 5 & 0.73 \\
\hline Someone who hugs you & 4.18 & 10.03 & I & 5 & 0.80 \\
\hline Someone to get together with for relaxation & 4.04 & 10.03 & I & 5 & 0.88 \\
\hline Someone to prepare you meals if you were unable to do it yourself & 3.96 & 10.17 & 1 & 5 & 0.70 \\
\hline Someone whose advice you really want & 4.06 & 0.96 & I & 5 & 0.81 \\
\hline Someone to do things with to help you get your mind off things & 4.00 & 0.99 & 1 & 5 & 0.85 \\
\hline Someone to help with daily chores if you were sick & 3.87 & 10.17 & 1 & 5 & 0.74 \\
\hline Someone to share your most private worries and fears with & 4.06 & 10.04 & 1 & 5 & 0.81 \\
\hline Someone to turn to for suggestions about how to deal with a personal problem & 4.07 & 10.00 & I & 5 & 0.79 \\
\hline Someone to do something enjoyable with & 4.08 & 10.01 & 1 & 5 & 0.87 \\
\hline Someone who understands your problems & 4.02 & 10.00 & 1 & 5 & 0.76 \\
\hline Someone to love and make you feel wanted & 4.18 & 10.02 & I & 5 & 0.79 \\
\hline \multicolumn{6}{|l|}{ Crisis Support ( $\alpha=0.847,3$ items) } \\
\hline Someone to help you if you were confined to a bed & 3.67 & 10.37 & I & 5 & 0.78 \\
\hline Someone you can count on to listen to you when you need to talk & 4.03 & 10.08 & I & 5 & 0.81 \\
\hline Someone to give you good advice about a crisis & 4.01 & 10.07 & I & 5 & 0.86 \\
\hline \multicolumn{6}{|l|}{ Items Removed From Analysis } \\
\hline Someone to take you to the doctor if you needed it & 4.II & 10.10 & I & 5 & - \\
\hline Someone to confide in or talk to about yourself or your problems & 4.22 & 0.94 & I & 5 & - \\
\hline
\end{tabular}

Notes: "a="None of the time"; $5=$ "all of the time".

Abbreviations: Max, maximum; Min, minimum; SD, standard deviation.

Table 4 Bivariate associations with likelihood of joining clinical studies

\begin{tabular}{|c|c|c|c|c|}
\hline Factor & Odds ratio $(95 \% \mathrm{Cl})$ & p-value & Prevalence ratio $(95 \% \mathrm{Cl})$ & $p$-value \\
\hline Age (ref $=<65$ years) & $1.18(0.68,2.05)$ & 0.6 & $1.10(0.80,1.52)$ & 0.6 \\
\hline Gender $($ ref $=m)$ & I.II $(0.58,2.14)$ & 0.7 & $1.06(0.72,1.58)$ & 0.8 \\
\hline Education (ref = Kindergarten-12) & $1.07(0.60,1.90)$ & 0.8 & $\mathrm{I} .04(0.74, \mathrm{I} .46)$ & 0.8 \\
\hline Relationship Status ( $\mathrm{ref}=$ single) & $1.10(0.64,1.90)$ & 0.7 & $1.06(0.77,1.45)$ & 0.7 \\
\hline Social Support & $0.98(0.75,1.29)$ & 0.9 & $0.99(0.83,1.17)$ & 0.9 \\
\hline Crisis Support & $0.94(0.72,1.24)$ & 0.7 & $0.97(0.83,1.13)$ & 0.7 \\
\hline Basic Ability & $1.29(0.82,2.02)$ & 0.3 & $1.12(089,1.42)$ & 0.3 \\
\hline Strength and Mobility & $\mathrm{I} .05(0.79, \mid .4 \mathrm{I})$ & 0.7 & $1.03(0.87,1.23)$ & 0.7 \\
\hline Social Ability & $1.27(0.88,1.84)$ & 0.2 & $1.12(0.92,1.36)$ & 0.3 \\
\hline Errand Transportation & $1.53(1.02,2.28)$ & $0.04 *$ & $1.24(1.00,1.54)$ & 0.05 \\
\hline
\end{tabular}

Note: ${ }^{*} p<0.05$.

Abbreviations: $\mathrm{Cl}$, confidence interval; $\mathrm{m}$, male; ref, reference.

associated with enrollment intention among participants under age 65 years $(\mathrm{OR}=1.21[0.76,1.93], p=0.4 ; \mathrm{PR}=1.13$ $[0.86,1.48], p=0.4)$. However, for those over 65 years, participants with greater Crisis Support were less likely to express intentions to join clinical trials $(\mathrm{OR}=0.57[0.34$, $0.98], p=0.04 ; \mathrm{PR}=0.81[0.68,0.96], p=0.02)$. The interaction between Crisis Support and age was significant in both models $(\mathrm{OR}=0.47[0.23,0.95], p=0.04 ; \mathrm{PR}=0.71[0.52$, 0.99], $p=0.04$ ); however, the interaction between relationship status and Basic Ability was only statistically significant in the robust Poisson model ( $\mathrm{OR}=0.25$ [0.06, 1.09], $p=0.07$; $\mathrm{PR}=0.44[0.23,0.86], p=0.02)$.

\section{Discussion}

Recent reviews of the impact of the NIH Revitalization Act on clinical trial participation reflect an ongoing need for greater numbers of African Americans in clinical studies. ${ }^{22}$ This study offered confirmation that socioecological factors, extending beyond psychosocial considerations, were predictive of enrollment in clinical trials among an older population of African Americans. Social support, high functioning, and mobility facilitate greater participation in clinical trials in geographic areas with trial availability. These findings are consistent with others that have identified environmental factors and social support as important for achievement of optimal health and 
Table 5 Results of multivariable logistic and robust Poisson regression models for factors associated with likelihood of joining clinical studies ( $\mathrm{n}=221$, missing $=30$ )

\begin{tabular}{|c|c|c|c|c|}
\hline \multirow[t]{2}{*}{ Factor } & \multicolumn{2}{|l|}{ Logistic model } & \multicolumn{2}{|l|}{ Robust Poisson model } \\
\hline & Odds ratio $(95 \% \mathrm{Cl})$ & $p$-value & Prevalence ratio $(95 \% \mathrm{Cl})$ & $p$-value \\
\hline $\operatorname{Age}^{\mathrm{a}}(\mathrm{ref}=<65$ years $)$ & $1.60(0.84,3.05)$ & 0.2 & $1.24(0.88,1.74)$ & 0.2 \\
\hline Gender $($ ref $=m)$ & $1.22(0.55,2.68)$ & 0.6 & I.II (0.7I, I.72) & 0.6 \\
\hline Education (ref $=$ Kindergarten-12) & $0.95(0.49,1.85)$ & 0.9 & $0.98(0.68,1.39)$ & 0.9 \\
\hline Relationship Status ${ }^{\mathrm{b}}(\mathrm{ref}=$ single) & $1.49(0.72,3.06)$ & 0.3 & $1.25(0.88,1.78)$ & 0.2 \\
\hline Social Support & $0.83(0.58,1.17)$ & 0.3 & $0.91(0.77,1.08)$ & 0.3 \\
\hline Crisis Support (age <65 years) & $1.21(0.76,1.93)$ & 0.4 & $1.13(0.86,1.48)$ & 0.4 \\
\hline Crisis Support (age $\geq 65$ years) & $0.57(0.34,0.98)$ & $0.04 *$ & $0.81(0.68,0.96)$ & $0.02 *$ \\
\hline Basic Ability (for single participants) & $3.25(1.16,9.10)$ & $0.03 *$ & $2.08(1.24,3.48)$ & $0.005^{*}$ \\
\hline Basic Ability (for participants with a partner) & $0.80(0.32,2.05)$ & 0.6 & $0.92(0.67,1.27)$ & 0.6 \\
\hline Strength and Mobility & I.II $(0.79,1.58)$ & 0.5 & $1.09(0.87,1.36)$ & 0.5 \\
\hline Social Ability & $1.77(1.09,2.87)$ & $0.02 *$ & $1.42(1.09,1.86)$ & $0.009 *$ \\
\hline Errand Transportation & $2.10(1.22,3.60)$ & $0.007^{*}$ & $1.57(1.13,2.19)$ & $0.008 *$ \\
\hline Interaction of Age and Crisis Support & $0.47(0.23,0.95)$ & $0.04 *$ & $0.71(0.52,0.99)$ & $0.04 *$ \\
\hline Interaction of Relationship Status and Basic Ability & $0.25(0.06,1.09)$ & 0.07 & $0.44(0.23,0.86)$ & $0.02 *$ \\
\hline
\end{tabular}

Notes: affect of age when Crisis Support is 0 (the mean factor score), beffect of Relationship Status when Basic Ability is 0 (the mean factor score), ${ }^{*} p<0.05$.

Abbreviations: $\mathrm{Cl}$, confidence interval; $\mathrm{m}$, male; ref, reference.

well-being among diverse older populations..$^{15,16,37-39}$ Our findings offer validation of the broader scope of issues that may be impacting older African Americans' willingness to participate in clinical trials.

We found that the examined sociodemographic factors were not significantly related to likelihood of joining a clinical study when functional impairment and social support were taken into account. Gender, age, education, and relationship status were not found to be significantly related to future enrollment intentions. Previous studies have demonstrated disparities among these factors in trial enrollment and in willingness to participate in trials among ill individuals. ${ }^{6,8,36,40,41}$ That these factors did not seem to affect willingness to participate in clinical trials among our cross-sectional sample of older church-going African Americans is an encouraging signal for inclusion of diverse older participants in future clinical trials. This homogeneity suggests that disparities in enrollment and willingness to participate in trials among patients do not necessarily reflect disparities in willingness of the population. Instead, they may arise from specific barriers to willingness of specific sick individuals, or from structural issues in trial enrollment that either increase disparity in enrollment or differentially affect willingness to participate. The findings suggest that ability to get to a clinical trial site (personally or through assisted transportation) was due to physical challenges, including mobility limitations, an issue well described in the literature. ${ }^{42}$

Most of the predictors of enrollment were related to functional impairment. Lower physical functional level, and dependency on others to facilitate access to clinics, may have greater impact on clinical trial enrollment than other commonly perceived factors such as historical distrust of medical research and lack of knowledge about the medical field. ${ }^{12-14,43}$ In turn, the lack of evidence for an association between social support and willingness to participate in research suggests that barriers may play a larger role in clinical trial enrollment than facilitators, a premise not yet thoroughly investigated in the literature. Even if individuals have adequate support for their enrollment decision (such as transportation and emotional support), the inability to get dressed in the morning is, understandably, a greater hurdle to overcome.

The associations with three of the four functional impairment factors indicate a high association between overall physical function and the willingness to participate in clinical trials. Within the entire sample, the higher ability scores as measured by Basic Ability, Social Ability, and Errand Transportation significantly predicted higher likelihood of joining a clinical study. Lack of availability of transportation to research sites has been previously identified as a barrier to trial participation in both qualitative and quantitative studies as well as our own. ${ }^{44}$ The degree to which logistical issues such as transportation access are barriers will likely be highly dependent upon local circumstances and environmental factors; within the urban setting of our study, they appear to be a concern.

It is understandable that the barriers associated with ability to perform daily tasks would also contribute to the decreased likelihood of joining any study. The types of physical abilities for these factors include components such as basic hygiene like bathing and dressing, getting out into the community, and driving and performing errands. These are skills that are needed to independently interact with and 
participate in the community ${ }^{15,38,39}$ as well as participate in a clinical trial. Prior research focuses on enrollment exclusions related to functional impairment, rather than the logistical aspects of participation. ${ }^{41}$ Our findings suggest that even when trials are designed to allow participation by older individuals with functional impairment, those individuals may be less likely to seek out trials when not directly referred. Researchers must be willing to logistically facilitate participation in order encourage participation.

Notably, among those $>65$ years of age, a lack of crisis support was a critically important factor that was predictive of intention to participate in trials. Studies with geriatric populations have identified crisis support teams as important aid for health care decision making, as they account for listening to concerns and offering input on dilemmas. ${ }^{45,46}$ Thus, having the ability to harness similar decisional support resources is an important consideration for those who may be facing much uncertainty, disability, or comorbidities in later life. Additionally, physicians perceive lack of home support networks for managing potential treatment side effects as a potential barrier to research participation among older patients, and as a potential barrier to actually attending appointments at which they may be referred or enrolled. ${ }^{41}$ However, older individuals lacking crisis support may have unique needs due to health issues they are facing, for which the crisis support measure may operate as a proxy. The support they envision receiving from providers and support staff conducting clinical trials, and their broader social network supporting their enrollment decisions, may therefore be an attractive perceived benefit that they associate with participation in clinical studies..$^{27,30,47,48}$

Our findings offer important guidance to investigators and their clinical research staff on successful recruitment strategies for older African Americans. Qualitative inquiry may augment these findings to offer important insight on social and functional issues encountered by this population and how to address these challenges. Foremost among the suggestions is to work with nursing or personal care aides to reach those who need added assistance with their living functions. This may be within residential communities or facilities that serve this population. In addition, the items related to a support system that includes both someone who listens and someone who gives advice hearkens to the strategy of partnering with trusted sources of care and community members who may have a broad reach among seniors. Thus, enlisting pastors and faith leaders in trial participation and recruitment might help address the barriers to participation among older seniors who are dependent on others for daily and crisis support. ${ }^{26,30}$

\section{Limitations}

We recognize the limitations of our study design that employed serial cross-sectional behavioral measures of which causality may not be directly determined. We also recognize the limitations of self-reported data, as participant, recall, and social desirability bias may have been a factor; however, previous research with elderly persons has shown that intention, while mediated by attitudes, is correlated to actual behavioral outcomes in both health behavior and volunteerism. ${ }^{49,50}$ Because our sample is drawn from older African Americans attending African American churches, our results may not generalize to older African Americans who are not church members. However, we feel that our study encompasses a significant portion of this population; a 2009 survey reported that $53 \%$ of African Americans of all ages attend church on a weekly basis; further, $64 \%-65 \%$ of African Americans ages $\geq 50$ years are affiliated with a historically Black/African American Christian church. ${ }^{51}$

\section{Conclusion}

This study found that previously unexplored factors such as physical/environmental and social issues may have on clinical trial recruitment potential among older African Americans. Our findings illuminate important implications for consideration of logistical issues, such as the role of transportation options and social support. In addition, the findings offer direction for the pursuit of other nontraditional venues to increase participation of those who are homebound or who are functionally impaired. Alternative recruitment venues such as nursing homes may be necessary to adequately incorporate participants who cannot be recruited in traditional settings. In addition, studies may need to be best adapted to operate in institutions where seniors reside, such as senior living facilities or nursing homes, to ensure full participation with fewer impediments.

\section{Acknowledgments}

We are grateful to the following pastors, health ministers, and program speakers: Doctors Candice Richardson, Cathy Hogan, Leticia Presley-Cantrell, Jessie Legros, Branden Evans, Charles Burton, Michael McHenry, and Don Rubin. We also thank Pastor Devon Ward, Elders Brian Green, Robert Dinkins, Gary and Sandra Reddish, Donna Tate, Nathaniel Smith, Nikia Braxton, Marcus Bolton, and Patrick Kelly. Finally, we would like to express our gratitude to all of the Dose of Hope church members for their willingness to volunteer part of their weekends to participate in our study. Our knowledge and understanding of clinical trial motivators has been greatly enhanced because of your insight and participation. 
Support for this study was provided by the US National Institutes of Health (5R03AG042831).

\section{Disclosure}

The authors report no conflicts of interest in this work.

\section{References}

1. Ford ME, Siminoff LA, Pickelsimer E, et al. Unequal burden of disease, unequal participation in clinical trials: solutions from African American and Latino community members. Health Soc Work. 2013;38(1):29-38.

2. Smedley BD, Stith AY, Nelson AR; Institute of Medicine. Unequal Treatment: Confronting Racial and Ethnic Disparities in Health Care; 2003.

3. Salman A, Nguyen C, Lee YH, Cooksey-James T. A review of barriers to minorities' participation in cancer clinical trials: implications for future cancer research. J Immigr Minor Health. 2016;18(2):447-453.

4. Kwiatkowski K, Coe K, Bailar JC, Swanson GM. Inclusion of minorities and women in cancer clinical trials, a decade later: have we improved? Cancer. 2013;119(16):2956-2963.

5. National Institutes of Health. NIH guidelines on the inclusion of women and minorities as subjects in clinical research. NIH Guide. 1994;23(11). Available from: https://grants.nih.gov/grants/guide/notice-files/not94100.html. Accessed March 17, 2017.

6. Murthy VH, Krumholz HM, Gross CP. Participation in cancer clinical trials: race-, sex-, and age-based disparities. JAMA. 2004;291(22):2720-2726.

7. Heiat A, Gross CP, Krumholz HM. Representation of the elderly, women, and minorities in heart failure clinical trials. Arch Intern Med. 2002;162(15):1682-1688.

8. Stewart JH, Bertoni AG, Staten JL, Levine EA, Gross CP. Participation in surgical oncology clinical trials: gender-, race/ethnicity-, and agebased disparities. Ann Surg Oncol. 2007;14(12):3328-3334.

9. Cooke CR, Erickson SE, Watkins TR, Matthay MA, Hudson LD, Rubenfeld GD. Age-, sex-, and race-based differences among patients enrolled versus not enrolled in acute lung injury clinical trials. Crit Care Med. 2010;38(6):1450-1457.

10. Seelig BJ, Dobelle WH. Altruism and the volunteer: psychological benefits from participating as a research subject. ASAIO J. 2001;47(1): 3-5.

11. Emanuel E, Wendler D, Grady C. What makes clinical research ethical? JAMA. 2000;283(20):2701-2711.

12. Banda DR, St. Germain S, McCaskill-Stevens W, Ford JG, Swain SM. A critical review of the enrollment of black patients in cancer clinical trials. In: Clinical Trials: 2012 Educational Book [Internet]. Alexandria VA: ASCO University; 2012. Available from: http://meetinglibrary.asco. org/content/88-114. Accessed March 17, 2017.

13. Brown RF, Cadet DL, Houlihan RH, Thomson MD, Pratt EC, Sullivan A, Siminoff LA. Perceptions of participation in a phase I, II or III clinical trial among African American patients with cancer: what do refusers say? J Oncol Pract. 2013;9(6):287-293.

14. Schmotzer GL. Barriers and facilitators to participation of minorities in clinical trials. Ethn Dis. 2012;22(2):226-230.

15. Levasseur M, Genereux M, Bruneau JF, et al. Importance of proximity to resources, social support, transportation and neighborhood security for mobility and social participation in older adults: results from a scoping study. BMC Public Health. 2015;15:503.

16. Rearden J, Hanlon AL, Ulrich C, Brooks-Carthon M, Sommers M. Examining differences in opportunity and eligibility for cancer clinical trial participation based on sociodemographic and disease characteristics. Oncol Nurs Forum. 2016;43(1):57-66.

17. Boggavarapu S, Sullivan KM, Schamel JT, Frew PM. Factors associated with seasonal influenza immunization among church-going older African Americans. Vaccine. 2014;32(52):7085-7090.
18. Niyibizi M, Schamel J, Frew PM. Neighborhood Influences on Reported Seasonal 2012-2013 Influenza Vaccination Among Older African Americans in Atlanta, Georgia. J Immunol Tech Infect Dis. 2016;5:2.

19. Haas S, Rohlfsen L. Life course determinants of racial and ethnic disparities in functional health trajectories. Soc Sci Med. 2010;70(2010):240-250.

20. Neru-Jeter AM, Thorpe RJ, Fuller-Thomson E. Black-white differences in self-reported disability outcomes in the U.S.: early childhood to older adulthood. Public Health Rep. 2011;126(6):834-843.

21. Thorpe RJ, Szanton SL, Bell CN, Whitfield KE. Education, income and disability in African Americans. Ethn Dis. 2013;23(1):12-17.

22. Murphy SL, Xu J, Kochanek KD. Deaths: final data for 2010. Natl Vital Stat Rep. 2013;61(4):1-118.

23. Chen MS Jr., Lara PN, Dang JH, Paterniti DA, Kelly K. Twenty years post-NIH revitalization act: enhancing minority participation in clinical trials (EMPaCT): laying the groundwork for improving minority clinical trial accrual: renewing the case for enhancing minority participation in cancer clinical trials. Cancer. 2014;120 (Suppl 7):1091-1096.

24. Centers for Disease Control and Prevention. Minority Health: Black or African American Populations. Atlanta, GA: US Department of Health and Human Services; 2013 [cited 2016 January 31]. Available from: http://www.cdc.gov/minorityhealth/populations/REMP/black. html-Disparities.

25. Oishi S. Socioecological psychology. Annu Rev Psychol. 2014;65: 581-609.

26. Frew PM, Schamel J, O’Connell KA, Randall LA, Boggavarapu S). Results of a Community Randomized Study of a Faith-Based Education Program to Improve Clinical Trial Participation among African Americans. Int J Env Res Public Health. 2015;13(1):ijerph13010041.

27. Frew PM, Omer SB, Parker K, et al. Delivering a "dose of hope": a faith-based program to increase older African Americans' participation in clinical trials. JMIR Res Protoc. 2015;4(2):e64.

28. Ajzen I. Understanding Attitudes and Predicting Social behavior. Englewood Cliffs, NJ.: Prentice-Hall; 1980: 278.

29. Frew PM, Archibald M, Martinez N, del Rio C, Mulligan MJ. Promoting HIV vaccine research in African American communities: does the theory of reasoned action explain potential outcomes of involvement? Challenge (Atlanta, GA). 2007;13(2):61-97.

30. Frew PM, Archibald M, Diallo DD, et al. An extended model of reasoned action to understand the influence of individual- and network-level factors on African Americans' participation in HIV vaccine research. Prev Sci. 2010;11(2):207-218.

31. Damschroder LJ, Aron DC, Keith RE, Kirsh SR, Alexander JA, Lowery JC. Fostering implementation of health services research findings into practice: a consolidated framework for advancing implementation science. Implement Sci. 2009;4:50.

32. Glass TA, McAtee MJ. Behavioral science at the crossroads in public health: extending horizons, envisioning the future. Soc Sci Med. 2006;62(7):1650-1671.

33. Grzywacz JG, Fuqua J. The social ecology of health: leverage points and linkages. Behav Med. 2000;26(3):101-115

34. Jette AM, Davies AR, Cleary PD, et al. The functional status questionnaire: reliability and validity when used in primary care. J Gen Intern Med. 1986;1(3):143-149.

35. Sherbourne CD, Stewart AL. The MOS social support survey. Soc Sci Med. 1991;32(6):705-714.

36. Durant RW, Legedza AT, Marcantonio ER, Freeman MB, Landon BE. Willingness to participate in clinical trials among African Americans and whites previously exposed to clinical research. J Cult Divers. 2011;18(1):8-19.

37. Debnam K, Holt CL, Clark EM, Roth DL, Southward P. Relationship between religious social support and general social support with health behaviors in a national sample of African Americans. J Behav Med. 2012;35(2):179-189.

38. Wilkie R, Peat G, Thomas E, Croft P. Factors associated with participation restriction in community-dwelling adults aged 50 years and over. Qual Life Res. 2007;16(7):1147-1156. 
39. Everard KM, Lach HW, Fisher EB, Baum MC. Relationship of activity and social support to the functional health of older adults. J Gerontol B Psychol Sci Soc Sci. 2000;55(4):S208-S212.

40. BeLue R, Taylor-Richardson KD, Lin J, Rivera AT, Grandison D. African Americans and participation in clinical trials: differences in beliefs and attitudes by gender. Contemp Clin Trials. 2006;27(6):498-505.

41. Townsley CA, Selby R, Siu LL. Systematic review of barriers to the recruitment of older patients with cancer onto clinical trials. J Clin Oncol. 2005;23(13):3112-3124.

42. Strupeit S, Wolf-Ostermann K, Buss A, Dassen T. Mobility and quality of life after discharge from a clinical geriatric setting focused on gender and age. Rehabil Nurs. 2014;39(4):198-206.

43. Tanner A, Kim SH, Friedman DB, Foster C, Bergeron CD. Barriers to medical research participation as perceived by clinical trial investigators: communicating with rural and African American communities. $J$ Health Commun. 2015;20(1):88-96.

44. Mills EJ, Seely D, Rachlis B, et al. Barriers to participation in clinical trials of cancer: a meta-analysis and systematic review of patient-reported factors. Lancet Oncol. 2006;7(2):141-148.

45. Vicente V, Sjostrand F, Sundstrom BW, Svensson L, Castren M. Developing a decision support system for geriatric patients in prehospital care. Eur J Emerg Med. 2013;20(4):240-247.
46. Boorsma M, Langedijk E, Frijters DH, Nijpels G, Elfring T, van Hout HP. Implementation of geriatric assessment and decision support in residential care homes: facilitating and impeding factors during initial and maintenance phase. BMC Health Serv Res. 2013;13:8.

47. Frew PM, Schamel JT, O’Connell KA, Randall LA, Boggavarapu S. Results of a community randomized study of a faith-based education program to improve clinical trial participation among African Americans. Int J Environ Res Public Health. 2015;13(1):ijerph 13010041.

48. Frew PM, Archibald M, Hixson B, del Rio C. Socioecological influences on community involvement in HIV vaccine research. Vaccine. 2011;29(36):6136-6143.

49. Wiesner M, Tesch-Romer C. Use of hearing aids by the elderly: correlation between intention and behavior. Z Gerontol Geriatr. 1996;29(4): 273-279.

50. Warburton J, Terry DJ. Volunteer decision making by older people: A Test of a Revised Theory of Planned Behavior. Basic Appl Social Psychol. 2000;22(3):245-257.

51. Sahgal N, Smith G. A Religious portrait of African-Americans: pew research center; 2009; Available from: http://www.pewforum. org/2009/01/30/a-religious-portrait-of-african-americans/. Accessed Feb. 18, 2017.
Open Access Journal of Clinical Trials

\section{Publish your work in this journal}

The Open Access Journal of Clinical Trials is an international, peerreviewed, open access journal publishing original research, reports, editorials, reviews and commentaries on all aspects of clinical trial design, management, legal, ethical and regulatory issues, case record form design, data collection, quality assurance and data auditing

\section{Dovepress}

methodologies. The manuscript management system is completely online and includes a very quick and fair peer-review system, which is all easy to use. Visit http://www.dovepress.com/testimonials.php to read real quotes from published authors. 